\section{O Gabinete Biométrico da Escola de Educação Física do Exército: medir e classificar para produzir corpos ideais, 1930-1940*}

\section{The Biometric Cabinet of the Escola de Educação Física do Exército: measuring and classifying to produce ideal bodies, 1930-1940}

\author{
Ana Carolina Vimieiro Gomes \\ Professora do Departamento de História/ \\ Universidade Federal de Minas Gerais. \\ Av. Antônio Carlos, 6627 \\ 31270-901 - Belo Horizonte - MG - Brasil \\ carolvimieiro@ufmg.br
}

\section{André Luiz dos Santos Silva}

Professor da Federação de Estabelecimentos de Ensino Superior em Novo Hamburgo.

Av. Dr. Maurício Cardoso, 510

93510-250 - Novo Hamburgo - RS - Brasil

andrels@feevale.br

\section{Alexandre Fernandez $\mathrm{Vaz}$}

Professor dos programas de pós-graduação em Educação e Interdisciplinar em Ciências Humanas/ Universidade Federal de Santa Catarina. Caixa Postal 476

Campus Universitário Trindade

88040-900 - Florianópolis - SC - Brasil alexfvaz@uol.com.br

Recebido para publicação em dezembro de 2011. Aprovado para publicação em abril de 2012.
GOMES, Ana Carolina Vimieiro; SILVA, André Luiz dos Santos; VAZ, Alexandre Fernandez. O Gabinete Biométrico da Escola de Educação Física do Exército: medir e classificar para produzir corpos ideais, 1930-1940. História, Ciências, Saúde - Manguinhos, Rio de Janeiro, v.20, n.4, out.-dez. 2013, p.1551-1569.

\section{Resumo}

Analisa práticas biométricas e biotipológicas do Gabinete Biométrico da Escola de Educação Física do Exército, Rio de Janeiro, presentes na Revista de Educação Física do Exército nas décadas de 1930 e 1940. Era preciso classificar, controlar periodicamente os resultados dos exercícios e medir aspectos morfológicos dos corpos. As classificações eram feitas segundo modelos estrangeiros, e buscava-se classificar tipo, qualidades e defeitos. A análise das práticas do Gabinete demonstra que biometria e biotipologia foram mobilizadas complementarmente pela educação física, objetivando a normatização dos corpos.

Palavras-chave: Brasil anos 1930 e 1940; Revista de Educação Física do Exército; biometria; biotipologia.

\section{Abstract}

This paper analyzes biometrical and biotypological practices of the Biometric Cabinet of the Escola de Educação Física do Exército (Physical Education School of the Army) in Rio de Janeiro in the 1930s and 1940s, published in Revista de Educação Física do Exército. It was necessary to classify, monitor the results of the exercises periodically and measure morphological aspects of the bodies. The classifications were made in accordance with foreign parameters and an attempt was made to classify by type, quality and defects. The analysis of the practices of the Cabinet shows that biometrics and biotypology were complementary aspects of physical education, aiming at the standardization of bodies.

Keywords: Brazil in the 1930s and 1940s; Revista de Educação Física do Exército; biometrics; biotypology. 
$\mathrm{E}^{\mathrm{n}}$ m julho de 1932, a Revista de Educação Física do Exército publica, assinado pelo médico militar doutor Sette Ramalho, o artigo intitulado "O Gabinete Biométrico na educação física moderna", em que o autor informa, especialmente aos oficiais de sua arma que visitavam o então chamado Centro Militar de Educação Física (CMEF), posteriormente Escola de Educação Física do Exército, sobre as atividades do Gabinete Biométrico. Havia quatro meses que funcionava no CMEF um curso de biometria a cargo do doutor Sette Ramalho. A criação do Gabinete era tida como um dos elementos centrais da proposta de educação do corpo naquela instituição, correspondendo à exigência de uma educação física moderna, fundamentada em conhecimentos científicos. O principal intuito para a existência do Gabinete, nas palavras de Sette Ramalho, era proteger seus educandos e, como se poderá observar, isso deveria acontecer por meio do controle, via o mais pleno conhecimento, dos corpos. As medidas antropométricas e fisiológicas garantiriam a adequação dos exercícios físicos que seriam realizados.

Evidências apontam para o fato de que as iniciativas de constituição de um gabinete de biometria para a educação física estavam relacionadas à emergência na ciência biomédica brasileira de duas áreas de conhecimento: a biometria e a biotipologia. Enquanto a primeira propunha medir variados caracteres morfológicos e fisiológicos dos indivíduos e tratava estatisticamente os dados para estabelecer distribuição de frequência e média numérica, a segunda, a partir desses mesmos dados, classificava os corpos em tipologias. Ao que tudo indica, ambas eram praticadas de maneira complementar e imbricada, tendo estado provavelmente envolvidas com as intenções de produção científica - não só na medicina - de certa normalidade para os corpos dos brasileiros e, com isso, com a definição de um tipo físico nacional, o que representava, como lemos nas palavras do médico Peregrino Júnior (1940, p.XIII), "alcançar, por fim, o ideal altíssimo das quatro grandes harmonias da Natureza": a do corpo, que seria a beleza; a do coração, a bondade; a do espírito, a inteligência; a das funções, a saúde, indispensáveis para a "grandeza e felicidade do país, no campo da produção, no campo da força, no campo do pensamento criador" (p.XIII).

Considerando esse contexto, o presente trabalho busca analisar algumas práticas científicas desses campos biomédicos realizadas no Gabinete Biométrico da Escola de Educação Física do Exército, no Rio de Janeiro, ao longo da década de 1930. Partimos de uma concepção de ciência como prática cultural, construída em interação com as visões de mundo e as demandas sócio-históricas de tempo e espaço específicos, que determinam as maneiras com que os homens, coletivamente, produzem conhecimento para interagir com o que se designa como natureza, representada, nesse caso, pelo organismo humano. Consideramos, portanto, que uma abordagem da 'ciência fazendo-se', ou seja, de suas práticas, pode ser reveladora da história de um conhecimento científico (Fleck, 2010; Golinski, 2005). Para tanto, tomamos como fontes primárias a produção científica dos médicos, civis e militares, envolvidos com estudos biométricos (com destaque para o médico militar doutor Sette Ramalho) divulgada na Revista de Educação Física do Exército, importante periódico da área, publicado ininterruptamente desde março daquele ano e com exceção do período de participação brasileira na Segunda Guerra Mundial, entre 1942 e 1945. Consideramos também livros e manuais de biometria relacionada à educação física daquele período.

Nosso argumento é o de que, num momento de amplo debate sobre identidade nacional ${ }^{1}$, a biometria na Escola de Educação Física do Exército foi conhecimento que, além de portador 
de status científico, era empreendido com vistas a "produzir pessoas" (Hacking, 2007, p.285)2 por meio da biologia dos corpos, ou seja, pelo escrutínio de características morfológicas e fisiológicas. Tem-se, assim, um modelo de ciência para a educação física que, ancorada em suposta objetividade, fornecia padrões para diferenciações e as hierarquizações dos corpos (Gould, 2003), favorecendo a operação com concepções preconceituosas a respeito do que seriam os tipos corporais normais e ideais para a prática dos exercícios físicos e do esporte e, quiçá, para os brasileiros.

\section{Fundamentos da biometria e a biotipologia}

O termo biometria, conforme descrito pelo médico Fernando R. da Silveira (1929, p.99), no primeiro Congresso Brasileiro de Eugenia, em 1929, diz respeito ao "conjunto de processos matemáticos empregados em Biologia". De forma semelhante, para o médico militar Augusto Sette Ramalho (1940, p.4), "biometria é a ciência que tem por fim traduzir numericamente os fenômenos biológicos, estabelecendo entre os dados assim obtidos relações que visam determinar as leis que os regem". Trata-se, então, de um campo de conhecimento configurado desde finais do século XIX e caracterizado pela "medida dos seres vivos" (Albrizio, 2007; p.102), cujo objetivo seria o estudo quantitativo da variação das características orgânicas das populações de plantas e animais, acabando por ser aplicado, por meio da medicina, à espécie humana. A partir dos diversos dados numéricos, que recebiam tratamento estatístico, pretendia-se que ela fosse um meio de determinar as leis que regem os fenômenos biológicos. Sendo assim, os estudos biométricos seriam uma forma de ordenar esses fenômenos, pois, como afirmado por Roquette-Pinto (1933, p.140), em Ensaios de antropologia brasiliana, "só eles permitem verificar, na enorme desordem aparente, os diferentes ritmos da criação". ${ }^{3}$ Nesses termos, podemos dizer que a biometria consiste, portanto, em uma proposta de biologia quantitativa, ou seja, é a materialização de um ideário nas ciências biomédicas com pretensões de objetivar e normalizar os fenômenos da vida.

No oitocentos, a biometria foi concebida como ciência cujos procedimentos de demonstração numérica e estatística tinham como intuito o estudo do processo de seleção natural darwinista. O cientista inglês Francis Galton (1822-1911), tido tradicionalmente como 'fundador' da eugenia, também praticava a biometria. ${ }^{4}$ Ele lançava mão dessas formas de quantificações da morfologia, bem como das capacidades e habilidades de animais e de humanos, para caracterizar aqueles animais, plantas e pessoas hereditariamente mais adaptados. Na verdade, grande parte dos estudos biométricos de Galton foi, acima de tudo, estudos antropométricos, que não se reduziam às medidas de qualidades físicas, mas se estendiam às faculdades mentais e comportamentais dos seres humanos. Uma vez identificadas as melhores características, seria então possível intervir eugenicamente no aperfeiçoamento das espécies, das raças, aí inclusa a humana. É nesse aspecto, aliás, que a biometria se ligava às teorias sobre a hereditariedade, uma vez que os atributos atávicos e - posteriormente, com as definições da genética mendeliana - os genes eram relacionados aos dados numéricos sobre caracteres físicos, mentais e comportamentais, produzidos e analisados estatisticamente em estudos biométricos, em grupos humanos (Bulmer, 2003). 
A biometria reunia, de maneira complexa, vários domínios de conhecimento ancorados em diversos modelos de quantificação dos fenômenos corporais. Suas práticas envolviam medidas morfológicas, ou seja, recursos da antropometria: mensuração do peso, da altura, das circunferências (tórax, membros, cabeça), de envergaduras etc. Muitas dessas práticas antropométricas pareciam recuperar e até refinar e radicalizar aquelas antes realizadas pela antropologia biológica (ou física) do século XIX (Blanckaert, 2001; Sá et al., 2008). A fisiologia também era mobilizada pela biometria: examinavam-se a pulsação, a capacidade respiratória, a força, a pressão arterial, entre outras medidas. Até mesmo a análise de composições químicas dos líquidos corporais, como urina e sangue, era, algumas vezes, incluída como elementos de suas práticas científicas. Ancoradas nos pressupostos da ciência experimental, as investigações biométricas, para alcançar essas quantificações, deveriam contar com uma série de equipamentos de medição, além de instrumentos para registros imagéticos dos corpos, realizando práticas que procuravam emprestar caráter de objetividade a seus procedimentos de medida (Daston, Galison, 2007).

Os dados biométricos (especialmente da antropometria) eram rearranjados e recebiam tratamento estatístico para a determinação das médias e padrões de normalidade. Esses procedimentos de categorização dos resultados numéricos dos corpos se relacionavam àqueles propostos pelo cientista belga Quetelet, em meados do século XIX, para a determinação do 'homem médio', do 'tipo médio'. Como debatido por Ian Hacking (1990), apesar de a palavra 'média' ter sido usada desde então para descrever uma distribuição de frequência dos dados numéricos, ela estaria relacionada a uma concepção do que seria o normal, ou seja, significaria uma regularidade dos fenômenos. Ao se delinear o normal, por extensão produzir-se-ia o desviante. Todavia, na medicina, desde o século XIX, além de representar o que seria o regular, o usual, o típico, o correto ou o bom - algo a ser preservado de desvios ou da patologia (Canguilhem, 2010) -, a normalidade associada à média estatística também foi representada como sinal de inferioridade. Isso porque, conforme proposto por Francis Galton, a partir de um ideário progressista e nas aplicações eugênicas de seus estudos biométricos, o normal foi tomado como algo a ser aperfeiçoado ainda mais (Hacking, 1990).

As quantificações estiveram vinculadas às qualificações dos corpos das pessoas. As medidas biométricas serviam também de base para a determinação de parâmetros de classificação: os biotipos. Nesse caso, constata-se que a biometria esteve diretamente relacionada a outro campo de conhecimento biomédico, e às vezes com ele se confundia: a biotipologia. Segundo o médico brasileiro Waldemar Berardinelli (1936, p.15), biotipologia foi o termo criado, nos anos 1920, pelo médico italiano Nicola Pende (1880-1970) para caracterizar a "ciência das constituições, temperamentos e caracteres", representando "a fase científica das doutrinas constitucionalistas". Ela seria então o enlaçamento da ciência experimental com o estudo da constituição humana. A biotipologia continuava e atualizava (segundo um discurso de pretendida maior cientificidade) as classificações antropológicas e criminológicas do século XIX, como aquelas dos médicos Cesare Lombroso e Paul Broca, praticadas a partir de mensurações e classificações das características mentais, dos traços físicos e craniométricos das pessoas. O determinismo biológico característico daquele século adotava esses critérios, vistos como científicos, na classificação dos desviantes, ou seja, degenerados, loucos e potenciais criminosos (Gould, 2003). 
Médicos brasileiros que advogavam a relevância da biotipologia diziam que nela o foco estava no indivíduo, no singular, sendo, portanto, a "ciência do indivíduo humano ... a ciência de cada homem em particular ... é a biologia comparativa dos indivíduos humanos" (Berardinelli, 1936, p.15). Enquanto a antropologia se dirigia à identificação dos traços comuns dos seres humanos para determinar as populações e os vários grupos humanos, a biotipologia buscava as diferenças entre os indivíduos. Se a fisiologia enfocava a função dos órgãos, e a microbiologia os agentes externos causadores das doenças, a biotipologia, aplicada à clínica médica, dedicava-se às especificidades corpóreas dos indivíduos no que se referia à propensão a desenvolver certas doenças (Albrizio, 2007). Sendo assim, após a análise e detecção do particular, ao mesmo tempo, afirmava-se que seria preciso o agrupamento das variações individuais de acordo com parâmetros de semelhança, ou seja, pela comparação e enquadramento dos indivíduos em tipos humanos predefinidos. ${ }^{5}$

Berardinelli (1933) afirmava ser a normalidade biológica um critério numérico e que ela deveria ser fundamentada pela estatística, segundo a lei da média de Quetelet-Gaus. Um indivíduo normal seria aquele cujos caracteres se aproximassem dessa média. Todavia, ele acrescentava que para uma prática médica em diálogo com a biotipologia, o que importava era o indivíduo. Segundo Berardinelli (1933, p.70), "a individualização exclui a normalidade”. Ele afirmava com isso que a normalidade estatística não era central e serviria apenas como parâmetro de comparação para "apreensão das infinitas variações individuais" (Berardinelli, 1933, p.71). ${ }^{6}$ Assim, podemos constatar que a ideia de fixar modelos biotipológicos, ancorada em pressupostos de matematização dos corpos, comportava certa ambivalência frente a tais discursos de individuação: tornava-se conveniente para enquadrar em padrões e normalizar homogeneizando o heterogêneo - ao mesmo tempo em que servia para diferenciar e detectar as individualidades.

Diversos modelos de qualificações, articulando as medidas morfológicas, funcionais e psicológicas, foram elaborados para agrupar os corpos dos indivíduos. Escolas biotipológicas em países europeus como França, Alemanha e Itália propuseram suas classificações. Entre as que aparecem frequentemente citadas pelos médicos brasileiros está a do francês Claude Sigaud (1862-1921) que, mobilizando dados morfológicos e fisiológicos, determinou quatro tipos humanos: respiratório, digestivo, muscular e cerebral. No primeiro tipo salienta-se a predominância do tórax e da parte média da face; no segundo, do abdômen e do andar inferior da face, sendo a cabeça em pirâmide; no terceiro, há uma repartição simétrica entre tórax e abdômen; no quarto tipo, a do crânio, com a cabeça em "forma de peão" (Berardinelli, 1936, p.42).

Outra escola mencionada é a do alemão Kretschmer (1888-1964) que, ao seguir um ponto de vista psicológico, relacionou os temperamentos e comportamentos aos aspectos morfológicos, determinando três tipos classificatórios: pícnicos, astênicos e atléticos. Os pícnicos seriam pessoas com corpos "rechonchudos, atarracados, face arredondada e musculatura mole". Caracterizar-se-iam por "acúmulo de gordura no pescoço, face e tronco, além de tendência a ser maníaco-depressivos". Os astênicos, por sua vez, apresentariam corpos "mais desenvolvidos em comprimento do que altura" e tendência a desenvolver esquizofrenia. Os atléticos seriam pessoas "esbeltas com extremidades longas e corpos robustos" (Berardinelli, 1936, p.205-206). 
Já a dita escola italiana parece ter sido o modelo mais adotado como referência para a biotipologia brasileira. ${ }^{7}$ De seus membros, Nicola Pende, Giacinto Viola e Mario Barbàra são os mais citados (Ferraz, Lima Junior, 1939; Ramalho, 1940; Berardinelli, 1936; Rocha Vaz, 1932). Viola, por exemplo, com base em dados morfológicos, propôs classificação a partir de três grupos: normoesplâncnico, megaloesplâncnico, microesplâncnico. O termo esplâncnico referia-se às proporções da região abdominal, com suas variações normais, acima (megalo) e abaixo (micro) desse padrão de normalidade (Berardinelli, 1936, p.115). Viola também propunha outra classificação, mas a partir da proporção numérica de medidas antropométricas, ou seja, da análise biométrica de alguns segmentos corporais: os normotipos, com simetria entre tronco, membros e abdômen; os braquitipos, com tronco maior que membros e abdômen maior que tórax; os longitipos, apresentando membros maiores que tronco e tórax maior que abdômen (Ramalho, 1940, p.93).

Além disso, para os biotipologistas italianos, sobretudo Nicola Pende, os parâmetros de referência corporal do homem médio, ou seja, normal, eram as estátuas gregas, pois consideravam que a coincidência do belo com a média equivaleria à coincidência do belo com o normal (Barbàra, 1929). O bom, o belo e o justo, como coincidentes, constituem um dos pilares da invenção da experiência ocidental. Esses modelos de perfeição foram atualizados desde o Renascimento, sendo o homem vitruviano o principal exemplo da retomada dessa referência estética (Terra, 2002). O século XIX restaura esse movimento de forma conservadora ao inventar, por exemplo, a tradição que liga o esporte contemporâneo à Antiguidade. Com isso, foi possível designar os 'feios', 'maus' e 'injustos', bem como, aqueles corpos dissonantes e desviantes, presentes em outras etnias. Podemos afirmar que o século XX radicaliza o uso das estátuas gregas, ao tomar as medidas dos segmentos corporais das estátuas como os parâmetros biométricos para os corpos humanos considerados ideais. Como destacado por Silva (2008), a recorrência às estátuas gregas pela educação física era um meio de legitimar um padrão de estética corporal ideal, por meio do uso de imagens reconhecíveis pelo senso comum.

Depreende-se que a biometria associada à biotipologia seria mais uma das formas de esboçar identidades de grupos humanos, traçando diferenciações e hierarquizações entre os corpos das pessoas e operando com concepções preconceituosas do que seriam os corpos ideais. Diante dessas constatações sobre os modelos científicos orientadores desses campos biomédicos, uma questão central se faz presente: como e por quais demandas - científicas, socioculturais e políticas - a biometria associada à biotipologia, naquele momento histórico, foi mobilizada pela educação física brasileira? Uma análise das práticas científicas do Gabinete de Biometria da Escola de Educação Física do Exército pode nos sugerir uma explicação.

\section{As práticas do Gabinete Biométrico da Escola de Educação Física do Exército}

Era preciso destinar atenção científica "ao conjunto de problemas biológicos colocados hoje pela prática da educação física e dos esportes", afirmava o médico francês Maurice Boigey (1939, p.7), na quarta edição de seu livro Manuel Scientifique d'Education Physique. Nas palavras do médico militar Augusto Sette Ramalho (1932, s.p.), no artigo “O Gabinete Biométrico na educação física moderna", a partir desse ponto de vista científico, a educação física teria variadas atribuições, sendo a principal delas "proteger seus educandos contra surpresas que 
poderiam ser as mais desagradáveis, se seus exercícios não se cercassem de sérias garantias. Entre essas exigências a constituição de um Gabinete Biométrico é dos mais prementes em face do papel que cabe a esse exercer".

Um dos meios de "proteger" os educandos e garantir a boa prática dos exercícios seria atentar nos aspectos biológicos das práticas corporais, pela 'apreciação do valor físico', conforme recomendação de Maurice Boigey. Isso seria feito por meio de exame médico completo, que compreendia mensurações e avaliações periódicas dos praticantes de exercícios pela realização de anamneses e exames clínicos, procedimentos então complementares às mensurações biométricas (Gomes, Dalben, 2011). Na Escola de Educação Física do Exército existia um Departamento Médico específico, que reunia médicos desportivos responsáveis pela realização periódica desses exames, especialmente nos soldados da tropa e nos próprios alunos (Tavares, 1933). Para tanto, havia instruções oficiais reguladoras específicas das atribuições do "médico de Educação Física" dos corpos da tropa e instituições militares (Revista... 1934, p.4-5). O Gabinete de Biometria era parte desse Departamento Médico.

O referido artigo do doutor Sette Ramalho é o primeiro de uma série sobre a biometria e a biotipologia presente na Revista de Educação Física do Exército ao longo da década de 1930. Esses textos eram relativos a práticas científicas, discussões de modelos teóricos e pesquisas originais que, a partir dos diversos referenciais das ciências biomédicas, tratavam das medidas e das classificações dos aspectos morfológicos e fisiológicos dos corpos. Tais medidas serviam como parâmetros do 'verdadeiro valor físico' das pessoas (a maioria das tropas do Exército ou alunos da Escola). A busca de tal 'valor físico' não envolvia somente a produção de dados quantitativos de aspectos morfofisiológicos para o controle dos progressos e da estagnação do 'valor físico' ou, ainda, a adaptação dos corpos ao exercício e aos esportes. Nos procedimentos científicos do Gabinete Biométrico, também estavam em jogo intervenções diagnósticas, por meio do levantamento de "dados clínicos em nosso país", o "estudo estatístico" e o traçado do tipo a que cada examinando pertence, "suas qualidades e seus defeitos" (Ramalho, 1932, s.p.).

Interessante notar que grande parte dos artigos da revista tinha caráter instrutivo, ou seja, apresentava os métodos de mensuração, os instrumentos utilizados na biometria, descrevia as fichas, sugeria procedimentos de realização dos testes, divulgava as avaliações feitas pelo Gabinete e debatia as escolas biotipológicas. A linguagem dos artigos apresentava tom didático, talvez visando a que o material servisse para o curso de educação física, como guia para os médicos do Exército realizarem os testes biométricos nas tropas e ainda como procedimentos para o controle médico-esportivo (Gomes, Dalben, 2011). Poucos traziam resultados das pesquisas científicas realizadas a partir dos testes, a exemplo do artigo do doutor Sette Ramalho (1939, p.28), intitulado “A correlação capacidade vital e estatura", no qual, por meio da apresentação de um estudo bioestatístico, mostra-se a possibilidade de se estabelecer uma 'lei constante' referente à relação entre a variação da capacidade vital (respiratória) e a estatura dos indivíduos.

Além de Sette Ramalho, outros médicos militares (e civis) igualmente publicaram artigos naquela revista, como Lauro B. Studart (1937), também instrutor de educação física, o que indica que não só o primeiro estava envolvido com a biometria na Escola do Exército. O capitão doutor Aureo Moraes também deve ser destacado por suas iniciativas de adaptação da mesa biotipológica de Viola, ou seja, pela criação de uma nova estrutura, de construção 
simples, com o intuito de facilitar a difusão das medidas biométricas e biotipológicas nas unidades militares (Moraes, 1937, p.29-30; Ramalho, 1940, p.111). Outro artigo que merece menção é o do médico civil doutor Floriano Peixoto Martins Sttofel (1937), docente da Faculdade Nacional de Medicina, que apresentou estudo original sobre o perfil biotipológico, realizado a partir de medidas de um grupo com mais de trezentas meninas de uma escola técnica secundária do Rio de Janeiro. Importante registrar que os resultados desse estudo foram apropriados por Waldemar Berardinelli (1942, p.626), que o considerou uma das contribuições já realizadas sobre os "normotipos brasileiros", uma vez que trataria da "silhueta da moça média de 15 anos do distrito federal", "quando está "entre menina e moça, entreaberto o botão e entrefechada a rosa".

Ainda não foi possível datar com exatidão um marco para o início das atividades do Gabinete de Biometria. Todavia, o Boletim do CMEF (posteriormente Boletim da Escola de Educação Física do Exército) de 18 de fevereiro de 1932 traz o anúncio e a descrição de uma série de aparatos e instrumentos médicos, muitos deles utilizados pela biometria, adquiridos pela instituição para compor o Gabinete de Fisiologia, que veio a ser o Departamento Médico daquela Escola. Além disso, o doutor Sette Ramalho, na Revista de Educação Física de julho de 1932, ao discorrer sobre o programa para o Gabinete, afirmou que eram, até aquele momento, apenas quatro meses de curso. Isso nos leva a supor que o Gabinete Biométrico reuniu condições de funcionamento por volta de março de 1932. Isso não significa que antes não houvesse qualquer atividade, pois o médico militar Aureo Moraes (1941), em artigo na revista Educação Física, assinala que a introdução da biotipologia no então CMEF foi empreendida pelo médico Agnelo Ubirajara da Rocha em 1931. Desde 1930 já constava no currículo do curso de medicina esportiva do CMEF a disciplina biometria, como é possível ver nos históricos dos alunos formados (Histórico..., 1929). Além disso, no Regulamento da Escola de Educação Física do Exército, datado de 1933, é possível observar a existência dessa disciplina como componente curricular e dos "Cursos de Instrutores de Educação Física", "Mestre de Armas" e "Medicina Especializada" (Estado-maior..., 1933).

Evidências apontam que a Escola de Educação Física do Exército parece ter sido um importante lócus de formação em biometria. Waldemar Berardinelli (1936, s.p.), biotipologista vinculado ao serviço do doutor Rocha Vaz na Faculdade de Medicina do Rio de Janeiro, por exemplo, se apresentava como "conferencista de biotipologia da Escola Militar de Educação Física". Os médicos Álvaro Ferraz e Andrade Lima Junior (1939), que realizaram um estudo biotipológico em soldados da Brigada Militar de Pernambuco, foram formados em medicina esportiva na Escola do Exército. Entre 1934 e 1939, como destacado por Vimieiro Gomes e Dalben (2011), a Escola Superior de Educação Física de São Paulo enviou alguns de seus alunos em excursão à Escola de Educação Física do Exército no Rio de Janeiro para assistir a aulas de biometria oferecidas pelo doutor Sette Ramalho. Para praticar a biometria era necessário o aprendizado dos conhecimentos e das técnicas específicas e padronizadas de tomada das medidas de cada aspecto morfológico e fisiológico do corpo (Revista..., 1933, s.p.).

No que se refere a sua estrutura de equipamentos, o Gabinete era composto por diversos 'ômetros, ímetros, ógrafos', utilizados nas práticas científicas da antropometria e da fisiologia experimental desde o século XIX. Como afirmado pelo doutor Sette Ramalho (1932, s.p.), "em um Centro especializado como o nosso, em que além de tudo se destina a pesquisas 
esclarecedoras da Educação Física, a aparelhagem será necessariamente mais completa". Isso envolvia a aquisição de "ergógrafos, esfimógrafos, polígrafos, relógios de Arsonval, miógrafos, cardiógrafos, etc. etc.". Além disso, para 'os corpos de tropas' outros aparatos, sobretudo de medidas morfológicas, eram necessários, entre eles: balança, toesa, compassos, quadros de envergadura, espirômetro, dinamômetro, cronômetro, tensiômetro etc., todos instrumentos que tornariam possível revelar alguns elementos específicos do valor físico dos indivíduos, a partir de parâmetros morfológicos e fisiológicos. Considerava-se que esses elementos se encarregariam

do estado de nutrição, como peso, colocado ao lado dos que nos fornecem a ideia do desenvolvimento, como a altura, os perímetros e os diâmetros; amparados pelos que nos vão dizer das qualidades funcionais das vísceras como os pulmões, já pelas sua capacidade vital, já pela apneia voluntária, já pelas pressões tomadas na inspiração e na expiração, já pelo número de movimentos respiratórios etc. ou como o coração, pela contagem do pulso, seu ritmo, suas qualidades, pela tensão arterial, pelas esfigmografias, cardiografias, etc., ou de sistema nervoso onde medimos até a velocidade da onda nervosa a percorrer estes fios que são os nervos ou o neuromuscular onde as contrações musculares são medidas e representadas graficamente etc. etc. (Ramalho, 1932, s.p.).

Observa-se que inerentes a essas práticas de mensuração do Gabinete estava implicado o controle minucioso e contínuo de cada parte dos corpos, tanto em seu aspecto somático como funcional. $\mathrm{O}$ intuito das medidas biométricas na educação física era revelar o 'perfil morfofisiológico' dos indivíduos em sua relação com a prática de exercícios físicos. Tal perfil:

é um verdadeiro retrato da forma e da função orgânicas do homem e por ele poderemos não somente classificá-lo como acompanhar mais detidamente, passo a passo, o seu desenvolvimento, nos dando ainda indicações preciosas para o aproveitamento esportivo. Ele nos dirá também das deficiências que necessitam ser corrigidas, de certas circunstâncias de momento que poderão impedir o aproveitamento de uma qualidade esportiva ou atlética natural e que, mediante correção, terá sua expansão no momento oportuno (Ramalho, 1932, s.p.).

Para reunir todo o volume de medidas dos corpos, exigido pelas práticas científicas da biometria, foram propostas fichas especiais, denominadas biométricas ou, algumas vezes, morfológicas ou morfofisiológicas. A preparação e o uso das fichas exigiriam "conhecimentos morfológicos modernos (Biotipologia), conhecimentos sobre Biometria Funcional e sobre Psicometria" (Ramalho, 1933a, p.3). Os dados deveriam ser dispostos de maneira separada, segundo cada um desses assuntos, para que não houvesse misturas e para facilitar a orientação da colheita das medidas biométricas. A sugestão do doutor Sette Ramalho (1933d, p.3) era que "se façam fichas impressas com os títulos e subtítulos dos aparelhos e órgãos a serem examinados". Ele chegou até a propor a instituição de uma Caderneta de Saúde para acompanhar "o interessado por toda a sua vida" com o intuito de registrar as alterações na saúde, as deformações e perturbações no seu corpo. Todavia, a utilização pelos médicos militares desse modelo de ficha em específico não era unânime. Em 1942, a Revista de Educação Física traz uma crítica, realizada pelo primeiro-tenente médico Washington Augusto de Almeida (1942, p.55), à falta de praticidade de tal ficha, em função "principalmente, da sua complexidade e minúcia", o que tornava o trabalho dos médicos extenso. 
Havia diferentes tipos de fichas, segundo o grupo a ser examinado. No corpo de tropa do Exército, além das medidas morfológicas e fisiológicas, enfatizavam-se as reações ao esforço, com, por exemplo, testes de corridas. Ao lado da tabela de dados corporais, existia outra, denominada "Traçado do perfil morfofisiológico", com escala de zero a dez, segundo a qual o médico deveria graduar cada uma das qualidades físicas medidas (Ramalho, 1933c). Interessante notar que o doutor Sette Ramalho a denominou ficha morfofisiológica tipo brasileiro (Almeida, 1942, p.55). Isso indica que ele próprio a elaborou a partir dos conhecimentos já existentes na área e os adaptou aos objetivos dos testes na tropa do Exército brasileiro.

$\mathrm{Na}$ capa desse tipo de ficha deveria ser também assinalada "COR ou raça", pois "em educação física, poderemos deixar de parte inteiramente a questão das raças?", perguntava Sette Ramalho (1933a, p.5), mostrando que nos procedimentos de medidas estava incluída a intenção de relacionar os tipos e formas corporais aos tipos étnicos. Nessa direção, outro critério de classificação étnica proposto em uma das fichas era a medida do "índice nasal" (p.4), muito utilizado pelos antropologistas, como um dos parâmetros corporais para a diferenciação étnica. Na biometria praticada no Exército, raça ou etnia parecia não ter centralidade, mantendo-se, todavia, como uma das várias categorias descritivas da biologia dos corpos das pessoas e que poderia ser prontamente mobilizada nas práticas de classificação. Em diálogo com o referencial evolucionista, mais voltado para o ambiente e a cultura (Santos, 2010) ${ }^{8}$, o médico Floriano Stoffel (1937), em artigo na Revista de Educação Física, chegou a afirmar que estava de fato em jogo não uma classificação racial por si, mas uma distribuição dos variados biotipos nas etnias ou raças:

Assim procedemos, rompendo com o classicismo que procura estudar os indivíduos, separando-os segundo o grau de pigmentação da epiderme, ou melhor, segundo as raças, palavra hoje sem significação e sem sentido, por estarmos convencidos de que não há nenhuma vantagem para a sociedade, nem ser expressão real a tão decantada superioridade de uma raça sobre outra ou grupo étnico sobre outro, pois temos visto que as diferenças, em alguns casos notadas, são devidas ao grau de civilização (Stoffel, 1937, p.17).

Outro tipo era a ficha morfológica para crianças, semelhante à dos adultos, mas cujo foco era a "observação do fenômeno do crescimento" (Ramalho, 1933b, p.42). Para a mensuração dos corpos de crianças o doutor Sette Ramalho indicava dois modelos. O primeiro conteria número suficiente de medidas para a análise do crescimento e levantamento de dados para a aplicação de exercícios físicos. O segundo seria reduzido, para "atender às necessidades de uma escola ou associação dispondo de pouco tempo e pouco recurso", o que permitiria também a realização de maior número de testes. Tinha ele objetivos ambiciosos ao elaborar tais fichas biométricas: "servir de base a estudos antropológicos da criança no Brasil" (p.4043). Para tanto, chegou a apelar às pessoas "que se encarregassem de tais mensurações para que enviem cópias de seus resultados ao nosso Gabinete de Biometria, onde elaboraremos diante de numerosas estatísticas, os quadros de 'máxima', 'mínima' e 'média' [parâmetros estatísticos usados pela biometria] das crianças do Brasil, nas diferentes idades e diferentes medidas" (p.42, destaques do original). Medidas biométricas em crianças eram realizadas como parte dos exames médicos durante as colônias de férias promovidas pela Escola de Educação Física do Exército. Na Revista de Educação Física podem ser observadas diversas 
imagens das crianças nas colônias de férias passando por avaliações, situação em que seus corpos eram medidos e classificados (Estudo..., 1936, p.16). O exame médico era considerado fundamental para orientar a educação física infantil, pois, conforme afirmava Sette Ramalho (1936, s.p.), servia para detectar "ora crianças normais física e psiquicamente, ora anormais", cabendo ao instrutor proceder com "as instruções atinentes a cada caso, de acordo com o que tiver observado". Não era objetivo dos testes biométricos comparar criança e adulto, mas determinar, pela análise estatística, "os tipos-padrão em cada idade e suas consequentes variações" (Ramalho, 1940, p.183). A biometria em crianças não era apenas questão de obtenção de "médias", mas do acompanhamento das transformações corporais, pois visava à "pesquisa dos elementos extremos compatíveis com o desenvolvimento normal em cada idade" (Ramalho, 1933b, p.42). ${ }^{9}$

Além do corpo de tropas e de crianças, os próprios alunos da Escola, fossem eles militares ou civis, também passavam pelos exames biométricos - bem como dos médicos e práticos quando do ingresso e ao longo de cada ano do curso. Tais exames serviam para "agrupamento dos indivíduos e verificação periódica da instrução", ou seja, para tentar estabelecer a homogeneização das turmas. Realizavam-se periodicamente na "16ª e 39å semana de instrução" (Gross, 1935, p.30).

O médico da tropa - de preferência com conhecimentos de educação física e esportes deveria ser o encarregado da tomada das medidas corporais dos soldados. Dado, porém, o número elevado de militares e em decorrência da necessidade do não prolongamento do número de dias reservados a exames, sugeria-se que fosse auxiliado por sargentos monitores, oficiais instrutores e sargentos anotadores. Com tal organização prática dos testes e utilizando a ficha prevista para o corpo de tropas, estimava-se que "um médico trabalhando duas horas por dia com todo o pessoal necessário poderá dar pelo menos cem (100) homens inteiramente medidos. Isso equivale a mil (1000) homens em 10 dias" (Revista..., 1933, s.p.). De crianças, a partir da ficha reduzida, seria possível realizar "trinta medições completas por hora, o que daria com um trabalho de três horas cerca de 100 crianças completamente medidas" (Ramalho, 1933b, p.42). Tais prospecções de realização de milhares de exames não só no Gabinete do Exército podem sugerir a existência, subjacente às práticas da biometria, de um anseio de estudo e ordenamento das características corporais dos brasileiros.

Nota-se que uma das práticas científicas da biometria era o levantamento de grande número de dados corporais que seriam posteriormente recombinados e até poderiam vir a receber tratamento estatístico. As práticas de quantificação dos corpos envolviam sobretudo a produção de médias, a elaboração de gráficos das funções corporais e o traçado do perfil morfofisiológico das pessoas. Ao combinar os dados corporais seria possível informar "sobre o conjunto do organismo": "o peso e a altura que viriam a completar a ideia de nutrição; a capacidade vital e o peso nos trariam a ideia da distribuição de Oxigênio pelos diversos tecidos". Combinados em maior número "apresentarão os diversos índices de robustez, tais como o célebre índice de Pignet em que entram o peso, a altura e os perímetros" (Ramalho, 1932, s.p.). No caso do traçado do perfil morfofisiológico, método de análise que parece ter sido adaptado pelo próprio doutor Sette Ramalho, "o indivíduo cujo equilíbrio morfológico fosse perfeito seria representado por uma linha reta, aquém, sobre ou além da média. Esse tipo seria ideal" (Revista..., 1933, s.p.). Desenhando-se o perfil seria possível revelar, com 
facilidade, "se há harmonia entre os diversos segmentos e funções, se há deficiências, se há qualidades aproveitáveis ou ainda se, ao lado dessas qualidades, existem defeitos que precisem ser corrigidos" (Sette Ramalho, 1933c, p.7). Esses procedimentos de medidas e de tratamento estatístico dos dados morfológicos e fisiológicos sugerem que, relacionada ao Gabinete Biométrico, pode ter havido a intenção de caracterizar um perfil corporal do brasileiro.

Cabe ressaltar que iniciativas de levantamento de dados corporais para estabelecer cientificamente um tipo físico nacional, ou seja, de normalização dos corpos brasileiros, não eram exclusivas do Gabinete de Biometria do Exército. No mesmo período, outros estudos biotipológicos foram realizados e tiveram seus resultados divulgados em diferentes publicações, sendo possível destacar o livro O normotipo brasileiro, do médico Isaac Brown (1934), resultado de estudo realizado a partir do Serviço do Prof. Rocha Vaz na Faculdade de Medicina do Rio de Janeiro. Outro que merece atenção é o livro A morfologia do homem do Nordeste, dos médicos militares Alvaro Ferraz e Andrade Lima Junior (1939), com os resultados de extenso estudo biotipológico em populações nordestinas, realizado por meio da avaliação de centenas de soldados do corpo de tropa da Brigada Militar de Pernambuco. Sette Ramalho (1941, p.8), após ser transferido para o 13을 Regimento de Infantaria em Ponta Grossa, realizou investigações, como o exame dos corpos de cerca de "800 conscritos julgados aptos para o serviço do Exército", que deram origem ao livro Antropologia do brasileiro do interior paranaense. Waldemar Berardinelli (1942), em Tratado de biotipologia e patologia constitucional, cita na seção "Tabelas de medidas normais brasileiras" o resultado de diversos trabalhos em crianças e adultos (dos dois sexos) realizados por outras instituições do Distrito Federal, no Instituto de Pesquisas Educacionais e no Museu Nacional (a partir dos estudos antropológicos de Roquette-Pinto ${ }^{10}$ ) e em outros estados, como São Paulo, e regiões do país, como Norte, Centro-sul e Nordeste.

Observamos que as práticas de mensuração corporal do Gabinete de Biometria estavam articuladas às de classificação da biotipologia. A própria ficha morfofisiológica para educação física, proposta pelo doutor Sette Ramalho (1033a, p.4), continha espaço para preenchimento de dados biotipológicos (ficha biotipológica) e, portanto, para a "classificação do indivíduo em um tipo ou subtipo biológico humano". O modelo de classificação adotado pelo Exército era o da dita escola italiana, principalmente a partir dos trabalhos do médico italiano Mario Barbàra, que propunha - ao adaptar a classificação proposta por Viola - os seguintes biotipos, combinando unicamente medidas de tronco e membros: longetipo, braquetipo (subtipos: antagônicos, harmônicos, excedentes e deficientes) e normotipo. O doutor Sette Ramalho (1933a, p.3) justificava sua escolha pelas seguintes razões, além dos "fins práticos": "(1a) suas ideias são as mais aceitas no nosso meio; ( $\left.2^{a}\right)$ os tipos e subtipos nela existentes abrangem a totalidade dos aspectos morfológicos humanos, podendo ser classificado qualquer indivíduo, o que não acontece nas outras escolas; (3a) finalmente - e aqui vai uma razão de grande alcance prático - ela traz um cunho biométrico característico que nos seduz". Em sua opinião, portanto, a classificação deveria coadunar-se com a quantificação dos corpos.

Observa-se mais uma vez que no Gabinete da Escola de Educação Física do Exército a biotipologia oferecia conhecimento científico complementar àqueles provenientes da biometria. Essa complementaridade era recíproca. Juntas, a quantificação e a qualificação dos corpos serviriam para normalizar e, com isso, detectar o que não estaria de acordo com uma norma corporal ideal. Ao se determinar o normal se produzia, concomitantemente, 
o desviante. Aqueles corpos que seriam considerados desacordes poderiam, pela educação física, ser controlados, corrigidos, melhorados e desenvolvidos por meio do exercício físico. Conforme afirmava Sette Ramalho (1933a, p.4), mais do que meros valores dos segmentos do corpo humano, com a prática da biometria associada à biotipologia, eram necessários:

Elementos que nos digam sobre as assimetrias passíveis de correção com o exercício.

Elementos que nos digam sobre deficiências em porções do corpo, passíveis de melhoras.

Elementos de controle dos efeitos de exercícios, a fim de que possamos acompanhar com exames periódicos o desenvolver de nossos educandos.

Elementos, finalmente, que visem fornecer relações numéricas capazes de completar o juízo morfológico, com dados não atingidos com a classificação biotipológica.

Também para Waldemar Berardinelli (1936, p.488) a "realização racional da educação física" exigia o conhecimento "morfofisiopsicológico dos indivíduos". Nesses termos, o objetivo principal do estudo biotipológico na educação física seria preventivo, ou seja, tratava-se de "tirar elementos para a classificação dos atletas e ginastas, respeitando as suas aptidões constitucionais" (Ramalho, 1933a, p.3). Era preciso "evitar que a prática dos esportes resulte mais nociva que vantajosa", argumentava Berardinelli (1936, p.495). Para tanto, fazia-se necessário "pesquisar na forma humana as suas melhores possibilidades atléticas, impedindo que persistam em uma especialidade". Por exemplo, os longilíneos "são tipos de velocidade; trabalham e tudo conseguem pela extensão da contração muscular." Entre os brevilíneos "se encontram mais facilmente indivíduos aptos ao manejo de grandes pesos, como os halterófilos" (Estudo..., 1936, p.5). Além disso, a biotipologia poderia ajudar na seleção dos "indivíduos bem dotados para o campionismo internacional e reconhecer precocemente em cada indivíduo, suas aptidões principais ou preferenciais para as diversas especializações esportivas" (Berardinelli, 1936, p.495).

Berardinelli (1936, p.9) também dirigia às mulheres suas prescrições, afirmando que era preciso atentar para "a tendência para a masculinização das formas da mulher moderna". Estudos demonstravam que "a constituição feminina, sobretudo nas mulheres esportistas, está se aproximando da constituição masculina". A educação física feminina deveria ser aquela que, por ser moderada, "traz grandes vantagens à mulher, corrigindo-lhe a gracilidade das formas, estimulando-lhe o desenvolvimento sexual, equilibrando-lhe o psiquismo, resultando, pois, uma melhora harmônica de todo o organismo". Constatamos mais uma das aplicações da biometria e biotipologia pela educação física, qual seja, normalizar para determinar os tipos físicos adequados para as diversas práticas corporais e modalidades esportivas, ou, inversamente, as práticas e modalidades adequadas para os tipos. ${ }^{11}$

Já no âmbito da educação física na escola, a biometria e biotipologia auxiliariam nos processos de constituição de turmas homogêneas. Partindo da premissa biotipológica de que os sujeitos devem ser estudados e estimulados em suas especificidades, considerava-se que as aulas de educação física seriam perniciosas se aplicadas indistintamente a todos os tipos físicos. Arthur Ramos (1936, p.36) recomendava como proposta de homogeneização que “o grupamento das crianças para essa educação será feito, então, não apenas por uma arbitrária e errônea divisão por idade cronológica, mas essencialmente por tipos morfológicos 
diagnosticados previamente pelo antropologista". As propostas educacionais deveriam estar em conformidade com as necessidades biológicas, em termos físicos, temperamentais e psíquicos.

\section{Considerações finais}

A análise de práticas científicas realizadas no Gabinete de Biometria da Escola de Educação Física do Exército, ao longo da década de 1930, demonstra que a biometria e a biotipologia foram campos dos conhecimentos biomédicos muito praticados, de maneira simbiótica e complementar, naquela instituição. Não eram apenas conteúdo científico do curso de formação de professores, monitores, instrutores e médicos do esporte, mas também parte do serviço de avaliação médica realizado em crianças, no corpo de tropa e nos próprios alunos da Escola. Neste último caso, elas foram um meio de avaliação da instrução ministrada ao longo do curso. Podemos estimar que, ao longo da década de 1930, no conjunto dessas operações empreendidas a partir das atividades médico-científicas do Gabinete de Biometria, milhares de pessoas tiveram seus corpos mensurados e classificados. Podemos observar que os médicos do Exército, envolvidos com a prática da biometria e da biotipologia, procuravam nos testes seguir os principais modelos científicos provenientes da Europa, além de readaptar e criar novos procedimentos para medição e classificação corporal dos brasileiros. Essa readaptação das práticas de medida e de classificação mostra-nos que a particularidade dos corpos dos brasileiros exigiu reinvenção e ajustes nos modelos, práticas e categorias classificatórias mobilizados a partir de escolas europeias. ${ }^{12}$

As ações do Gabinete fazem ver que naquela instituição as medidas quantitativas dos parâmetros antropométricos, seguindo a biometria, estavam sempre imbricadas às práticas de classificação dos corpos das pessoas, seguindo e adaptando os modelos da biotipologia, sobretudo da 'escola italiana'. Por isso, argumentamos que a biometria praticada na Escola do Exército fundamentava-se em um modelo classificatório, pois, a partir dos dados numéricos morfológicos e funcionais levantados nos estudos, menos se enfocava uma produção de médias ou normalidades estatísticas e mais se priorizava a qualificação dos corpos de cada pessoa e, ao mesmo tempo, por extensão, de um determinado grupo da população (em termos de sexo, idade, etnia e região do país).

Nas classificações sempre eram tomados como referência determinados parâmetros de corpos vislumbrados como ideais. Tais práticas de classificação podem ser consideradas meios de intervenção política nos corpos de cada indivíduo e, por consequência, no corpo social, ou seja, na população brasileira. ${ }^{13}$ Ao demarcar uma regularidade corporal, elas instituiriam parâmetros de avaliações e, quiçá, de distinção e controle do desviante, do anormal, a partir da referência de uma norma corporal predefinida e avaliada como a mais adequada a determinado grupo e sociedade. Como afirmado por Sette Ramalho (1941, p.53) se "os médicos militares" conseguissem produzir trabalhos biométricos "completos e instrutivos", realizariam "uma obra de grande alcance nacional, dando ao Brasil um melhor conhecimento do brasileiro nos seus defeitos, para corrigi-los, e nas suas qualidades, para aproveitá-las em benefício da Pátria comum". Tendo em vista o contexto histórico do Estado Novo, quando se acirraram os debates sobre 'identidade nacional' e quando a ciência foi por vezes mobilizada como 
fundamento de um projeto político para a nação (Duarte, 2010) ${ }^{14}$, é possível supor que essa interação (e, por vezes, a confusão) entre as práticas desses dois campos de conhecimento, pelo exame de um número significativo de pessoas no Gabinete da Escola de Educação Física do Exército, esteve relacionada aos interesses da época em caracterizar, cientificamente, um tipo físico nacional ideal. Num amálgama de conhecimentos técnico-científicos e concepções políticas nacionalistas, podemos inferir que a biometria no Exército serviu para produzir padrões objetivos na procura de uma normalização dos corpos dos brasileiros (Foucault, 2001).

É importante ressaltar que a determinação racial ou étnica não foi procedimento central da biometria praticada naquele espaço. Raça ou etnia, sobretudo pela indicação da cor da pele ou do índice nasal, figuraram como um dos vários parâmetros biológicos que estavam imbricados às classificações biométricas e biotipológicas. Sette Ramalho (1941, p.9), em estudo posterior sobre a antropologia dos paranaenses, considerava que não existia "uma raça branca ou uma raça negra", mas várias raças brancas ou negras. A intenção era, sobretudo, posicionar e diferenciar os tipos segundo parâmetros étnico-raciais. Um procedimento a ser realizado nos estudos biométricos seria colocar, lado a lado, os dados corporais levantados em cada indivíduo para comparar as características físicas dos: "faiodérmicos com leucodérmicos, faiodérmicos com melanodérmicos, faiodérmicos com xantodérmicos, e leucodérmicos com melanodérmicos" (Stoffel, 1937, p.17). Cabe ressaltar que cada uma dessas denominações consistia em um suposto tipo antropológico brasileiro, fundamentada na classificação proposta por Roquette-Pinto (1933), tendo como referência a classificação étnica e a coloração da pele, entre os vários aspectos biológicos analisados por aquele antropólogo.

Os médicos militares e civis envolvidos com a prática da biometria no Gabinete do Exército dialogavam com os pressupostos das ciências da hereditariedade e do racialismo. Como afirmado por Berardinelli (1936, p.18), era preciso "estar a par das diferenças individuais hereditárias". Segundo Sette Ramalho (1941, p.9), para avaliar raças era preciso ter definidas "características correlativas, hereditariamente transmissíveis e convencionalmente admitidas como caracterizadoras", que seriam capazes de diferenciar os grupos humanos. Entretanto, podemos sugerir que, como alguns eugenistas e antropologistas físicos brasileiros, os biometristas e biotipologistas do Gabinete do Exército, embora demonstrando diálogo com pressupostos mendelistas, segundo os quais as características genéticas seriam elementos determinantes para o desenvolvimento das especificidades da constituição de cada pessoa, tendiam, ao mesmo tempo, para uma abordagem muito mais próxima ao neolamarckismo, preconizando que fatores mesológicos e culturais poderiam ser alguns dos aspectos responsáveis pela configuração das diferenças biológicas entre os humanos (Stepan, 2005; Santos, 2010). Floriano Stoffel (1937, p.17) denominou tal concepção "critério sociológico de responsividade", ou seja, o meio, na longa duração, seria "fator preponderante na estruturação do indivíduo, imprimindo-lhe características que são comuns a todos quanto se encontram sob a sua influência". Podemos depreender que a esse pressuposto científico subjazia uma concepção preventiva e certo otimismo quanto às possibilidades de se configurar uma identidade corporal e tipológica própria para os brasileiros, porém uma identidade no plural (Cunha, 1999). Isso deveria ocorrer mediante intervenções e controle dos corpos, após o diagnóstico dos problemas e desvios nos parâmetros físicos tidos como ideais, por meio do levantamento de dados biométricos e práticas de classificação da população. Contudo, 
menor ênfase em debates racialistas ou racistas não implica que a esse discurso primando a normalidade não estivessem subjacentes iniciativas de produção de diferenças entre os grupos humanos e de hierarquização dos corpos das pessoas. Ao se propor o que seria normal e ideal, os desviantes poderiam ser estigmatizados.

Um olhar sobre as práticas científicas do Gabinete Biométrico revela que, naquela época, a biometria e a biotipologia foram mobilizadas pela medicina que se ocupava da educação física brasileira como forma de controle dos corpos para a prática de exercícios e esportes. Além disso, algumas evidências permitem supor que esses saberes e práticas serviram como fundamentos para uma tentativa de caracterização de um perfil morfofisiológico e biotipológico de parte da população do Distrito Federal e, talvez, em projeto mais amplo e ambicioso, da população brasileira.

\section{NOTAS}

* Este artigo é resultante de pesquisas financiadas pelo Conselho Nacional de Desenvolvimento Científico e Tecnológico, pela Fundação de Amparo à Pesquisa do Estado de Minas Gerais e pela Coordenação de Aperfeiçoamento de Pessoal de Nível Superior/Deutscher Akademischer Austauschdienst, aos quais os autores agradecem.

${ }^{1}$ A década de 1930 é momento de forte tonalidade nacionalista, que se intensificou com a instauração do Estado Novo. Buscou-se compreender e afirmar 'o nacional', tendo em vista aquelas características étnicas, sociais e culturais que lhe eram próprias, nativas. Um dos aspectos muito discutidos pela intelectualidade brasileira do período foi a 'raça', tido como fundamental na definição de um desejado 'caráter nacional', ora branqueado, ora mestiço, biológica e culturalmente (Leite, 1976; Ortiz,1985; Herschman, Pereira, 1994; Cunha, 1999).

${ }^{2}$ Ian Hacking (2006) propõe a expressão making up people para compreender como os procedimentos de classificação científica da medicina podem produzir tipos de pessoas, concebidas e vivenciadas como uma maneira de ser. Para esse autor as classificações científicas, ao longo do tempo, desenvolveram uma 'máquina de produzir pessoas' cujas engrenagens são: a contagem, a quantificação, a criação de normas, a correlação estatística, a medicalização, a biologização, a genética, a normalização, a burocratização e a reivindicação por identidade. Consideramos que as práticas da biometria são compostas de algumas dessas engrenagens.

${ }^{3}$ Sobre Roquette-Pinto ver Lima e Sá (2008).

${ }^{4}$ Outros nomes relacionados à biometria são o do matemático Karl Pearson e do biólogo W. Weldon. Ambos foram responsáveis pela publicação de um periódico especializado, criado em 1901, intitulado Biometrika, do qual Galton era editor (Bulmer, 2003).

${ }^{5}$ Ao longo da década de 1930 travou-se intenso debate acerca do grupamento homogêneo dos alunos para a prática de educação física. A Revista Educação Física, editada por civis, e a Revista de Educação Física, por militares, divulgaram diversos artigos alimentando a discussão. Outro espaço de debate foi sétimo Congresso Nacional de Educação, realizado no Rio de Janeiro em 1935 e promovido pela Associação Brasileira de Educação. Nas páginas dos Anais (Congresso..., 1935) do evento é possível perceber que essa edição do congresso centrou-se no 'problema da educação física'. Na sessão de inauguração do Congresso o doutor Arthur Ramos (1936, p.37) apresenta a conferência "A educação física elementar sob o ponto de vista da caracterologia", em que aponta como um problema educacional a constituição de classes heterogêneas de acordo com orientações iguais. Dentre suas conclusões destaca-se "O simples critério de grupamento dos escolares por idade cronológica ou escolar não basta. Ela deve ser estabelecida dentro do critério caracterológico, no seu tríplice aspecto morfológico, temperamental e psicológico". Longe de ter sido um tema à parte, o grupamento homogêneo estabelece diálogo com a maioria das conferências do evento.

${ }^{6}$ Justamente por causa dessa ênfase sobre o indivíduo em sua constituição biológica peculiar, Juvenil Rocha Vaz (1932) chegou até a propor que a biotipologia fosse a base para se estabelecer novos rumos da medicina, título de seu livro sobre medicina constitucional e biotipologia, publicado em 1932.

${ }^{7}$ Nesse mesmo período, em outros países da América Latina, como México e Argentina, a 'escola italiana' também serviu como modelo científico para a prática da biotipologia (Stern, 2005; Miranda, 2003).

${ }^{8}$ Como destacado por Santos (2010), um deslocamento de olhar para o ambiente e cultura não significou o completo abandono de concepções do determinismo biológico e raciais para interpretar a dinâmica social 
brasileira ou a perda de certa ambiguidade nas interpretações que ora enfatizavam as desigualdades entre as raças, ora negavam as hierarquias entre os grupos humanos.

${ }^{9}$ Importante destacar que alguns anos mais tarde, Humberto Ballariny (1942, p.30-33) explica um dos motivos da organização pelo Exército da colônia de férias Filhos do Morro, qual seja, regenerar a raça por meio da eugenia.

${ }^{10}$ Roquette-Pinto (1933) no primeiro Congresso Brasileiro de Eugenia publicou estudo em que procurou determinar os tipos antropológicos da população brasileira, a partir de medidas antropométricas, com as quais criou uma classificação própria. Ele concluiu que no Brasil predominavam quatro grupos: leucodermos (brancos), faiodermos (branco + negro), xantodermos (branco + índio) e melanodermos (negros).

${ }^{11}$ Como destacado por Gomes e Dalben (2011), as avaliações biométricas, em conjunto com as classificações biotipológicas, também eram importante recurso científico para o 'controle médico-esportivo' empreendido no Departamento de Educação Física do Estado de São Paulo.

${ }^{12}$ Essas reapropriações denotam o que Ian Hacking (2006) caracteriza como efeito looping, ou seja, a classificação científica pode interagir com as pessoas classificadas, e estas, por sua vez, de volta, podem interferir e produzir ajustes nas categorias classificatórias originais. Lipphardt e Niewöhner (2007) propõem que nessas interações dinâmicas do processo classificatório estão envolvidas questões não só científicas, mas também de ordem social, política e moral.

${ }^{13}$ Sobre biodeterminismo, medicina legal e controle social no contexto da criminologia paulista nas décadas de 1920-1940, ver Ferla (2009).

${ }^{14}$ Regina Horta Duarte (2010) analisou os debates empreendidos por cientistas do Museu Nacional, como Roquette-Pinto e Mello Leitão, entre 1926-1945, para elaborar um projeto de nação em que a biologia, desdobrada em biomedicina, entomologia, eugenia etc., foi saber decisivo para fundamentar os anseios nacionalistas em jogo naquele contexto.

\section{REFERÊNCIAS}

ALBRIZIO, Angelo.

Biometry and anthropometry: from Galton to constitutional medicine. Journal of

Anthropological Sciences, Roma, v.85, p.101-123. 2007.

ALMEIDA, Washington Augusto.

Ficha biométrica simplificada para os corpos de tropa e estabelecimentos militares. Revista de Educação Física, Rio de Janeiro, n.53, p.55-60. 1942.

BARBÀRA, Mario.

Il fundamenti della biotipologia umana. Milano: Instituti Editorialli Scientifico.1929.

BALLARINY, Humberto.

Porque e como organizamos a colônia de férias

"Tudo pelo Brasil". Educação Física, Rio de

Janeiro, n.64, p.30-33. 1942.

BERARDINELLI, Waldemar.

Tratado de biotypologia e patologia constitucional. Rio de Janeiro: Francisco Alves. 1942.

BERARDINELLI, Waldemar.

Biotypologia: constituição, temperamento, caracter. Rio de Janeiro: Francisco Alves. 1936.

BERARDINELLI, Waldemar.

Noções de biotipologia. constituição, temperamento, caracter. Rio de Janeiro: Francisco Alves. 1933.
BLANCKAERT, Claude.

Lógicas da antropotecnia: mensuração do homem e bio-sociologia (1860-1920). Revista Brasileira de História, São Paulo, v.21, n.41, p.145-156. 2001.

BOIGEY, Maurice.

Manuel scientifique d'éducation physique. Paris: Masson. 1939.

BROWN, Isaac.

O normotypo brasileiro. Rio de Janeiro: Guanabara. 1934.

BULMER, Michael G.

Francis Galton: pioneer of heredity and biometry. Baltimore: John Hopkins University Press. 2003.

CANGUILHEM, Georges.

O normal e o patológico. Rio de Janeiro: Forense Universitária. 2010.

CONGRESSO..

Congresso Nacional de Educação, 7., 23 jun.-7 jul. 1935, Rio de Janeiro. Anais..., Rio de Janeiro: Associação Brasileira de Educação. 1935.

CUNHA, Olívia Maria Gomes.

Sua alma em sua palma: identificando a "raça" e inventando a nação. In: Pandolfi, Dulce (Org.). Repensando o Estado Novo. Rio de Janeiro: Editora FGV. p.257-288. 1999. 
DASTON, Lorraine; GALISON, Peter.

Objectivity. New York: Zone Books. 2007.

DUARTE, Regina Horta.

A biologia militante: o Museu Nacional, especialização científica, divulgação do conhecimento e práticas políticas no Brasil, 1926-1945. Belo Horizonte: Editora UFMG. 2010.

ESTADO-MAIOR...

Estado-maior do Exército. Regulamento da Escola de Educação Física do Exército. Rio de Janeiro: Imprensa Militar. 1933.

ESTUDO...

Estudo morfológico dos atletas: aplicação das formas aos desportos. Revista de Educação Física do Exército, Rio de Janeiro, n.33, p.5-6. 1936.

FERLA, Luis.

Feios, sujos e malvados sob medida: a utopia médica do biodeterminismo. São Paulo: Alameda. 2009.

FERRAZ, Alvaro; LIMA JUNIOR, Andrade. A morfologia do homem do Nordeste: estudo biotipológico. Rio de Janeiro: José Olympio. 1939.

FLECK, Ludwik.

Gênese e desenvolvimento de um fato científico: introdução à doutrina do estilo de pensamento e do coletivo de pensamento. Tradução Georg Otte, Mariana Camilo de Oliveira. Belo Horizonte: Fabrefactum. 2010.

FOUCAULT, Michel.

Os anormais: cursos no Collège de France (19741975). São Paulo: Martins Fontes. 2001.

GOLINSKI, Jan.

Making natural knowledge: constructivism and the history of science. Chicago: Chicago University Press. 2005.

GOMES, Ana Carolina Vimieiro; DALBEN, André. O controle médico-esportivo no Departamento de Educação Física do estado de São Paulo: aproximações entre esporte e medicina nas décadas de 1930 e 1940. História, Ciências, Saúde - Manguinhos, Rio de Janeiro, v.18, n.2, p.321-335. 2011.

GOULD, Stephen Jay.

A falsa medida do homem. São Paulo: Martins Fontes. 2003.

GROSS, João Carlos.

O exame físico: provas práticas. Revista de Educação Física, Rio de Janeiro, n.29, p.30-32. 1935.

HACKING, Ian.

Kinds of people: moving targets. The tenth British Academy Lecture, 11 Apr. 2006.
Proceedings of the British Academy, London, v.151, p.285-318. 2007.

HACKING, Ian.

The taming of chance. Cambridge: Cambridge University Press. 1990.

HERSCHMAN, Micael M.; PEREIRA, Carlos Alberto M.

A invenção do Brasil moderno: medicina, educação e engenharia nos anos 20 e 30. Rio de Janeiro: Rocco. 1994.

\section{HISTÓRICO...}

Histórico escolar de ex-alunos do Centro Militar de Educação Física, turma de 1929. (Arquivo da Escola de Educação Física do Exército, Rio de Janeiro). 1929.

LEITE, Dante Moreira.

O caráter nacional brasileiro. São Paulo: Pioneira. 1976.

LIMA, Nísia Trindade; SÁ, Dominique Miranda. Antropologia brasiliana: ciência e educação na obra de Edgar Roquette-Pinto. Belo Horizonte: Editora da UFMG; Rio de Janeiro: Editora Fiocruz. 2008.

LIPPHARDT, Veronika; NIEWÖHNER, Jörg. Producing difference in an age of biosociality: biohistorical narratives, standardisation and resistance as translations. Science, Technology and Innovation Studies, Edinburgh, v.3, p.45-65. 2007.

MIRANDA, Marisa A.

La antorcha del cupido: eugenesia, biotipología y eugamia en Argentina, 1930-1970. Asclepio, Madrid, v.55, n.2, p.231-255. 2003.

MORAES, Aureo.

Contribuição à história da educação física no Brasil: ligeiro relato sobre as atividades médicoesportivas do último decênio. Revista Educação Physica, Rio de Janeiro, n.56, p.26-29. 1941.

MORAES, Aureo.

Contribuição ao desenvolvimento da biotipologia no Brasil. Revista de Educação Física, Rio de Janeiro, n.35, p.29-30. 1937.

ORTIZ, Renato.

Cultura brasileira e identidade nacional. São Paulo: Brasiliense. 1985.

PEREGRINO JUNIOR, João.

Biotipologia pedagógica. Rio de Janeiro: Odeon. 1940.

RAMALHO, Augusto Sette. Antropologia do brasileiro do interior paranaense. Rio de Janeiro: Laemmert. 1941.

RAMALHO, Augusto Sette.

Lições de biometria aplicada. v.1. Rio de Janeiro: Papelaria Velho. 1940. 
RAMALHO, Augusto Sette.

A correlação capacidade vital e estatura. Revista de Educação Física, Rio de Janeiro, n.45, p.28-29. 1939.

RAMALHO, Augusto Sette.

O exame médico da educação física da criança, pelo método francês. Revista de Educação Física, Rio de Janeiro, n.33, p.10. 1936.

RAMALHO, Augusto Sette.

Das fichas biométricas: técnicas para a escolha e organização de dados biométricos e sua disposição em uma ficha de educação física. Revista de Educação Física, Rio de Janeiro, n.10. p.3-5. 1933a.

RAMALHO, Augusto Sette.

Fichas para crianças. Revista de Educação Física do Exército, Rio de Janeiro, n.8, p.42-46. 1933b.

RAMALHO, Augusto Sette.

Representação gráfica das qualidades

biomensuráveis: perfis. Revista de Educação Física, Rio de Janeiro, n.10, p.6-7. 1933c.

RAMALHO, Augusto Sette.

Ficha morfológica tipo-brasileiro a ser adotada nos corpos de tropa e estabelecimentos militares. Revista de Educação Física, Rio de Janeiro, n.6, s.p. 1933d.

RAMALHO, Augusto Sette.

O Gabinete Biométrico na educação física moderna. Revista de Educação Física, Rio de Janeiro, n.3, s.p. 1932.

RAMOS, Arthur.

Educação física elementar sob o ponto de vista da caracteriologia. Revista de Educação Física, Rio de Janeiro, n.33, p.35-36. 1936.

REVISTA...

Revista de Educação Física, Rio de Janeiro, n.15, p.39-40. 1934.

REVISTA...

Revista de Educação Física, Rio de Janeiro, n.6, s.p. 1933.

ROCHA VAZ, Juvenil.

Novos rumos da medicina. Rio de Janeiro:

Guanabara. 1932.

ROQUETTE-PINTO, Edgard.

Ensaios de antropologia brasiliana. São Paulo: Companhia Editora Nacional. 1933.

SÁ, Guilherme José da Silva et al. Crânios, corpos e medidas: a constituição do acervo de instrumentos antropométricos do
Museu Nacional na passagem do século XIX para o XX. História, Ciências, Saúde - Manguinhos, Rio de Janeiro, v.15, n.1, p.197-208. 2008.

SANTOS, Ricardo Ventura.

Mestiçagem, degeneração e viabilidade de uma nação: debates em antropologia física no Brasil (1870-1930). In: Maio, Marcos Chor; Santos, Ricardo Ventura. Raça como questão: história, ciência, identidades no Brasil. Rio de Janeiro: Editora Fiocruz. 2010.

SILVA, André Luiz dos Santos.

A perfeição expressa na carne: a educação física no projeto eugênico de Renato Kehl, 1917 a 1929.

Dissertação (Mestrado) - Escola de Educação

Física, Universidade Federal do Rio Grande do Sul, Porto Alegre. 2008.

SILVEIRA, Fernando R.

Biometrica. In: Congresso Brasileiro de Eugenia, 1., 30 jun.-7 jul. 1929, Rio de Janeiro. Actas e trabalhos. Rio de Janeiro: Academia Nacional de Medicina. p.99-106. 1929.

STEPAN, Nancy Leys.

A hora da eugenia: raça, gênero e nação na América Latina. Rio de Janeiro: Editora Fiocruz. 2005.

STERN, Alexandra M.

Mestizofilia, biotipologia y eugenesia em el México pos-revolucionario: hacia una historia de la ciencia y el Estado, 1920-1960. In: Armus, Diego. Avatares da medicalizacíon en America latina, 1870-1970. Buenos Aires: Lugar Editorial. 2005.

STOFFEL, Floriano.

Biotipologia. Revista de Educação Física, Rio de Janeiro, n.37, p.17-24. 1937.

STUDART, Lauro.

Índices biométricos femininos. Revista de Educação Física, Rio de Janeiro, n.35, p.25-28. 1937.

TAVARES, Luiz. da Silva.

O exame médico-desportivo. Revista de Educação Física do Exército, Rio de Janeiro, n.12, p.12-13. 1933.

TERRA, Vinicius Demarchi Silva.

Pedaços do tempo, gestos partidos: memórias do corpo em movimento na fotografia de Etienne-Jules Marey. Dissertação (Mestrado) Faculdade de Educação, Universidade Estadual de Campinas, Campinas. 2002.

\section{$\rightarrow \rightarrow \infty<\ll$}

